\title{
Difficulty in SLI diagnosis: A case study of identical twins
}

\author{
JODI TOMMERDAHL \& MARGUERITE DREW \\ University of Birmingham, South Birmingham NHS PCT, UK
}

(Received 26 October 2006; accepted 16 fune 2007)

\begin{abstract}
This paper examines identical 12-year-old twins with language difficulties, one of whom falls into the diagnostic remit of SLI while the other does not due to IQ differences. Further diagnostic testing was carried out and their language was analysed to determine whether their diagnoses were reflected by different linguistic abilities. Results show a strong similarity in linguistic profiles, leading to a questioning of IQ use in SLI diagnosis.
\end{abstract}

Keywords: Specific language impairment, language disorder, cognitive referencing, diagnostic criteria

\section{Introduction}

The label of specific language impairment (SLI), widely used by researchers and clinicians, is a controversial one. "SLI" normally refers to children with poor language skills, which are incommensurate with other areas of the child's development. SLI therefore differs from the more general category of "language impairment" by requiring the exclusion of several factors that could provide reasons for the language disorder such as low nonverbal IQ, hearing impairment, autism or the existence of known neurological damage (Leonard, 1998, p. 3). The idea that linguistic systems can be damaged while the speaker's cognition is spared is key to this definition of SLI, but is also the source of great debate (Whorf, 1956; Chomsky, 1975). The practice of diagnosing SLI based on a discrepancy between language scores and IQ is known as cognitive referencing (Cole, Dale, \& Mills, 1992; Krassowski \& Plante, 1997; Eadie, 2004). This paper presents a case study of identical twins whose linguistic situations call the use of cognitive referencing into question in terms of assigning diagnostic labels.

The normal IQ limit called for in order to diagnose SLI (Rice, Tomblin, Hoffman, Richman, \& Marquis, 2004) is typically defined as being a minimum of 85 points (Stark \& Tallal, 1981; Leonard, 1998, p. 16; Botting, 2005). However, the degree of discrepancy between IQ and language required by researchers and clinicians is variable (Aram, Morris, \& Hall, 1993; Records \& Tomblin, 1994). The lack of standard criteria for diagnosis makes direct comparison of groups across studies impossible (Aram et al., 1993; Tomblin et al., 1997).

Correspondence: Jodi Tommerdahl, School of Education, The University of Birmingham, Birmingham B15 2TT, UK. E-mail: j.tommerdahl@bham.ac.uk 
Despite lack of agreement regarding the definition, utility, and even existence of SLI, its cognitive referencing aspect is used in many clinics internationally and often plays a role in deciding the amount and type of therapy a child may receive (Cole et al., 1992; Schoenbrodt, Kumin, \& Sloan 1997; Bishop, 2004, p. 310). If it turns out that SLI is not an independent category of language impairment, or that the criteria used in its diagnosis are unreliable, then it is problematic that this diagnosis is used in planning intervention. Some researchers have described the very use of the SLI label as a possible "impediment to progress"' (Ors, 2002).

This paper addresses the question of whether real linguistic differences exist between those diagnosed with SLI and those diagnosed with a more general LI (language impairment) due to low IQ. Farrell and Phelps (as cited in Botting, 2005, p. 318) find that children with SLI, despite having normal IQs, still had lower average IQ scores than children with normal language development, giving rise to the question of whether LI and SLI are simply different ranges on a continuum. Unfortunately, few studies have compared the language of the two groups, and children with SLI are much more often compared with MLU and age controls (see Eadie, 2004, pp. 194-196, for list and discussion.).

Perhaps the strongest arguments against the use of IQ testing in SLI diagnosis, particularly in older children, come from results reported indicating that IQ scores of language-impaired children fluctuate throughout their formative years (Bishop \& Adams, 1990; Cole et al., 1992; Tomblin, Freese, \& Records, 1992; Krassowski \& Plante, 1997; Mawhood, Howlin, \& Rutter, 2000; Botting, 2005). Krassowski and Plante's (1997) study of 75 children from 3 to 11 showed at least a 5-point change in IQ over 3 years. The authors emphasized the fact that children may move in and out of the diagnostic category of SLI. Botting's (2005) study of IQ scores of 82 children with SLI showed a mean IQ of 108 at age 8 years, which dropped to 83 by age 14 .

Whereas the term specific in SLI has led to much debate, the term language may represent a more appropriate emphasis, given that all agree language is affected in language impairment (LI). It is therefore useful to look at research paradigms underlying this simple fact. One powerful tool for coming to terms with language impairments is the linguistic profile. Detailed linguistic analyses will add to our knowledge of whether distinct types of impairment exist or whether impairments are as individual as the children who live with them. This perspective may encourage professionals to analyse the language of each child as opposed to fitting the child into a diagnostic category, allowing greater suitability of therapy. This view is expressed by de Villiers (2002, p. 429) stating "Linguistics promises the best current analysis of the categories and principles of importance in language" and that "work on child language pathology must keep abreast of these discoveries because they hold the prospect of illuminating puzzling co-occurrences of symptoms" (pp.425-426). Guendouzi (2003) also uses linguistic analyses, which reveal marked linguistic differences in the profiles of two boys diagnosed with SLI, thereby questioning the utility of the term.

\section{Background of the children}

The twins had been assessed in the months immediately preceding this study by the speech and language therapist in their school. Their results are presented in Table I.

The British Picture Vocabulary Scale (Dunn, Dunn, Wheklan, \& Pintillie, 1982) is a measure of vocabulary which is independent from reading skills. The Clinical Evaluation of Language Fundamentals-Revised (CELF-R; Semel, Wiig, Secord \& Sabers, 1987), which examines language production and comprehension, shows their age equivalent scores to be 
Table I. Results of assessment.

\begin{tabular}{lll}
\hline Assessment Tool & \multicolumn{1}{c}{ Edward } & \multicolumn{1}{c}{ Henry } \\
\hline BPVS & $<1^{\text {st }}$ percentile & $<1^{\text {st }}$ percentile \\
CELF-R receptive & $70 \mathrm{ss} 2^{\text {nd }}$ percentile & 59 ss $1^{\text {st }}$ percentile \\
- Oral directions & $5 \mathrm{ss} 5^{\text {th }}$ percentile & $5 \mathrm{ss} 5^{\text {th }}$ percentile \\
- Word classes & $4 \mathrm{ss} 2^{\text {nd }}$ percentile & $3 \mathrm{ss} 1^{\text {st }}$ percentile \\
- Semantic relationships & $7 \mathrm{ss} 16^{\text {th }}$ percentile & 4 ss $2^{\text {nd }}$ percentile \\
- Comparative & $7 / 8$ & $6 / 8$ \\
- Spatial & $2 / 5$ & $1 / 5$ \\
- Passive & $5 / 8$ & $3 / 8$ \\
- Temporal & $2 / 7$ & $0 / 7$ \\
CELF-R expressive & $9\left(\mathrm{sum}\right.$-ss) $1^{\text {st }}$ percentile & 15 (sum-ss) $1^{\text {st }}$ percentile \\
- Formulated sentences & $3 \mathrm{ss} 1^{\text {st }}$ percentile & $3 \mathrm{ss} 1^{\text {st }}$ percentile \\
- Recalling sentences & $3 \mathrm{ss} 1^{\text {st }}$ percentile & $3 \mathrm{ss} 1^{\text {st }}$ percentile \\
- Word association & $3 \mathrm{ss} 1^{\text {st }}$ percentile & $9 \mathrm{ss} 37^{\text {th }}$ percentile \\
& Expressive language $=50$ & Expressive language $=57$ \\
CELF-R overall & $1^{\text {st }}$ percentile & $1^{\text {st }}$ percentile \\
- Total language score & 56 ss & 61 ss \\
- Age equivalent & $6 ; 0$ & $6 ; 5$ \\
Ravens & $14^{\text {th }}$ percentile & $5^{\text {th }}$ percentile \\
\hline
\end{tabular}

Notes: BPVS $=$ British Picture Vocabulary Scale; CELF-R $=$ Clinical Evaluation of Language FundamentalsRevised; ss=standard score.

$6 ; 0$ and $6 ; 5$ which are very similar given their chronological age of $12 ; 3$. While the receptive score shows Edward's comprehension as somewhat better than Henry's, close analysis reveals a very similar pattern of strengths and weaknesses. Edward's higher score is mostly due to his performance on the "Semantic Relationships" subtest. Their raw scores follow an identical pattern, with Edward answering one or two more questions correctly on each section.

In expressive scores, the tables are turned and Henry scores slightly higher than his brother. The only notable difference is their scores in the word association section. The therapist believed Edward performed poorly here due to not understanding the instructions when asked to name members of the semantic categories: how to get from one place to another and kinds of work. When explained in a subsequent therapy session, Edward performed almost identically to his brother, indicating that Edward's ability is probably closer to his brother's than what is reflected in the table.

The Raven's Progressive Matrices test (Raven, 1998) is not an "official" IQ measurement, but is often used as a rough guide to cognitive ability (Botting, 2005). Edward scored near the lower borderline of having a normal IQ, whereas Henry scored below the normal range. If the Ravens test is an accurate measure of IQ, this would result in Edward meeting the diagnostic criteria of SLI while Henry would not.

Although both boys had serious difficulties with vocabulary, language production and comprehension, neither displayed problems with intelligibility, fluency, phonology or pragmatics. Teacher interviews showed both boys were perceived as having weak academic skills, with Edward considered as noticeably weaker, the opposite of what might be expected in light of the Raven's scores. This study was devised to better understand the boys' cognitive and linguistic abilities. Specifically, this study aimed to:

(1) determine whether one or both boys could be diagnosed with SLI based on classic cognitive referencing using official IQ tests administered by a psychologist and defining a normal IQ as being from 85-115; 
(2) analyse the boys' level of grammatical ability using the LARSP analysis (Crystal, Fletcher, \& Garman, 1976; Crystal, 1982) to determine whether the similarity or difference found in their diagnoses is reflected in their language structure; and

(3) question to what degree cognitive referencing is helpful in determining the nature of linguistic impairment and in planning appropriate therapy.

\section{Methods}

\section{Participants}

The participants are identical twin brothers, aged 12;3. Interviews with the mother indicated both boys were in good health and that all other developmental milestones had been met within a usual timeframe. Both were given statements at age two due to absence of language. They produced their first single words at age 3 or 4 . No other known language difficulties exist in the family, which includes a sister of 18 months. Both had attended language units, albeit with poor attendance, and lived in a monolingual English environment. Their developmental problems seem to be limited to language.

\section{Procedure}

With informed consent from a parent, the children were assessed individually. On separate days, IQ tests were given by a clinical psychologist and 30-minute naturalistic language samples were recorded according to LARSP conventions (Crystal, 1982).

\section{Measures}

IQ. The performance section of the WISC-R (Wechsler, 1974) was administered by a psychologist. The Performance Scale (non-verbal) IQ is reported as having an internal consistency reliability coefficient of .90 and a test-retest stability coefficient of .90 .

Grammatical measure. The LARSP (Language Assessment, Remediation and Screening Procedure) (Crystal et al., 1976) is a linguistic profile which subjects a child's language to a "comprehensive and consistent linguistic analysis" (Ball, 1999) to describe a child's grammatical strengths and weaknesses. The LARSP was chosen specifically for its ability to analyse spontaneous language in contrast to tests which attempt to elicit particular language structures. Its focus on grammar and morphology had particular relevance due to the boys' marked difficulties in these areas and given that these areas are commonly associated with SLI.

\section{Results}

IQ tests. Results of the WISC-R closely mirror the Raven's scores. Edward's score was 86 while Henry's was 73. Using strict diagnostic criteria of a normal IQ (85-115) and language 2 SDs below the norm, Edward falls into the category of SLI while Henry's IQ is too low for this diagnosis. 
Language tests. On the following charts (i.e. Figure 1), only the sections with the greatest relevance to syntactic patterns are included. The LARSP chart is divided into stages, which run from 9 months to $4 ; 6+$ years. Both boys are shown to have expressive syntax skills reaching stage III in clause and phrase levels, which is typical of children from 2 to $2 ; 6$ years.

Phrase level. Examination of stages II to V reveals similar, but disordered, patterns in the boys' linguistic repertoires. At phrase level, both boys use a very limited number of adjectives. Both use D Adj $\mathrm{N}$ at stage III, but only rarely. Neither use two adjectives sequentially nor use nouns in an adjectival sense to create phrases like "a basketball game". Both rely primarily on $\mathrm{DN}$, and $\operatorname{Pr} \mathrm{D} \mathrm{N}$ phrases. Between the boys, a sole example exists of two phrase elements linked by a connector such as "boys and girls" (XcX on the chart).

Clause level. Again, we see that both boys display comparable but abnormal patterns. Both have the majority of their clausal constructions at stage III and rely heavily on SVC, SVO, and SVA constructions, although Edward has two instances of VOA structures. The expansion line between stages III and IV show that both of the boys are expanding clause elements beyond one word, with both boys expanding all five types of clause elements.

The boys perform nearly identically at the stage IV. Both are limited to the constructions of SVOA, SVCA and AAXY with no instances of SVOC or indirect objects. Given the sample size, the number of constructions used here is very small.

At stage V, the level representing what Crystal (1982, p. 33) calls "the development of complex sentence formation" through coordination and subordination, we see the boys' most complex sentences:

Henry: I don't think that one goes but I don't know/ this is lightning and they ain't got no home/

Edward: she's putting it on her hand to cool it down/ that's go first cuz they're moving in/

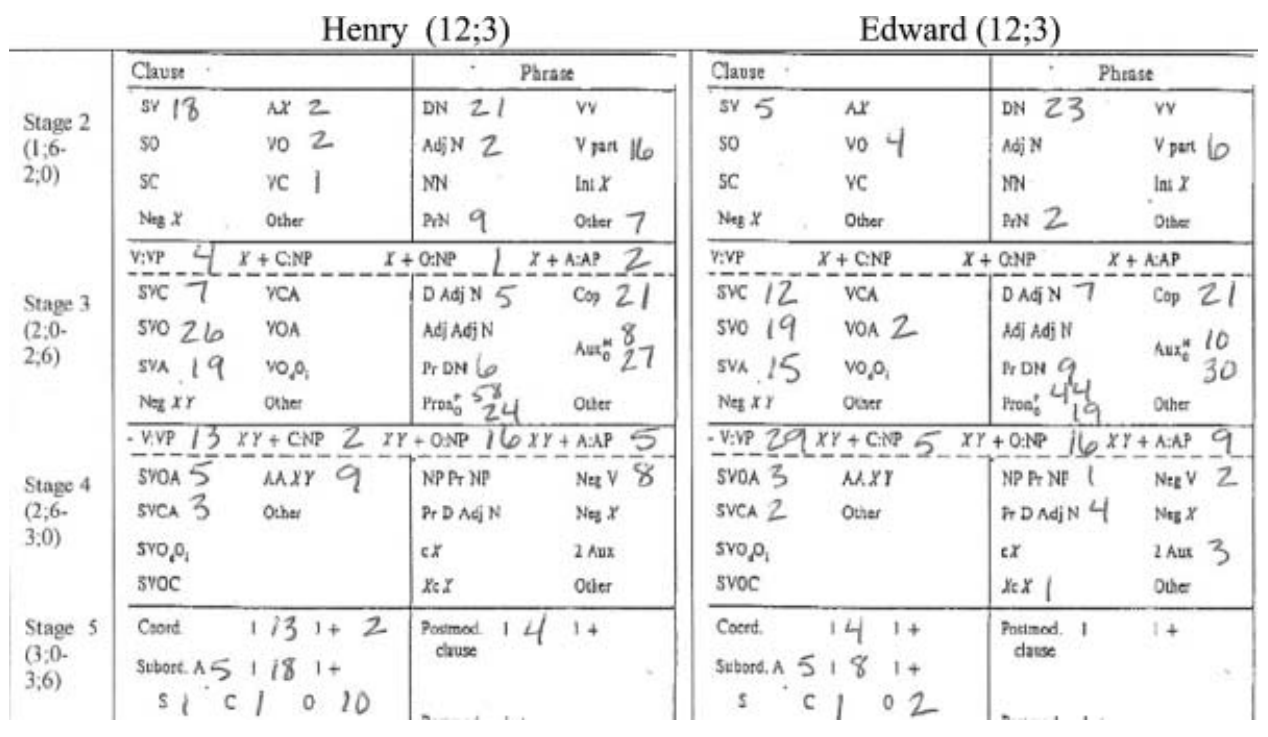

Figure 1. LARSP charts (excerpts). 
Both boys succeed in using coordination and subordination of clauses at times, but these clauses, even when syntactically correct, are often limited by their semantic and logical form, limiting their meaning. Edward's fewer errors at this level are likely to be due to the fact that he attempts them less often than Henry.

Word level. Word level on LARSP explores morphosyntactic ability. The profile on the left of table II illustrates the expected morphological profile of a normal 3-year-old according to Crystal (1982, p. 27). The other columns show Henry's and Edward's profiles.

As the order of normal morpheme acquisition is reflected in the order of the chart, the presence of low numbers in the beginning or centre of the chart may indicate disorder. The morphemes "-ing", "-pl", "“aux" and "“cop" are developing normally, but that the past (-ed) and the past participle (-en) are very rare for both boys. Neither uses the genitive form. The use of " $n$ ' $t$ " is the only area where the boys differ to a notable extent. Unsurprisingly, neither boy uses comparative or superlative forms of adjectives. Normal language acquisition varies between children and different developmental paths normally lead to the same point of competence. This makes it all the more surprising to see such similar samples of disordered language. The fact that these samples belong to identical twins supports the idea of a degree of biological influence on language development, but it is beyond the scope of this paper to expand on such assertions.

It is clear that both boys have serious difficulties with verb morphology; most striking is the near absence of the past tense in their speech. In many cases when the past tense was required, both boys repeatedly used the present progressive tense, usually with a contracted auxiliary. This verb form appears to be the default tense for both boys.

Edward: she's scalding herself/ she's washing her hands/ they're building a house/

Henry: they're spraying it out/ the lightning's setting the fire/ she's writing/

Deeper analysis into the boys' verb use is possible and appropriate, but constraints on space do not allow them to be reported in this paper.

\section{Discussion}

The first aim of this paper was to determine whether either or both of the boys could be diagnosed with SLI based on classic cognitive referencing. Using strict requirements of a

Table II. LARSP word-level profiles for a typical three-year-old, Henry (non-SLI), and Edward (SLI).

\begin{tabular}{lcl}
\hline Typical 3-year-old & Henry (non-SLI) & Edward (SLI) \\
\hline -ing 25 & -ing 20 & -ing 22 \\
pl 14 & pl 10 & pl 11 \\
-ed 21 & -ed 2 & -ed 2 \\
-en 10 & -en 2 & -en 4 \\
3s 7 & 3s 14 & 3 s 5 \\
gen 8 & gen 0 & gen 0 \\
n't 21 & n't 8 & n't 0 \\
'cop 18 & 'cop 17 & 'cop 12 \\
'aux 28 & 'aux 19 & 'aux 32 \\
-est 3 & -est 0 & -est 0 \\
-er 1 & -er 0 & -er 0 \\
-ly 2 & -ly 0 & -ly 2 \\
\hline
\end{tabular}


minimum IQ of 85 and a language score of 2 SD or more below the norm, it was determined that Edward met the requirements for SLI diagnosis while Henry did not.

The second aim was to determine whether the difference in the boys' diagnoses was mirrored by a difference in the structure of the language they used. The LARSP showed both the twins to be at Stage III (age equivalent $2 ; 0-2 ; 6$ ) for both clause and phrase level, with signs of expansion into stages IV and V. Both twins produced very similar language structures at clause, phrase and word level. Striking similarities were seen in the choice and frequency of structures used. Their expansions matched very closely and their morphological patterns were nearly indistinguishable.

The final aim of this paper was to ask to what degree IQ tests and linguistic analyses are helpful in describing language difficulties and making decisions regarding therapy. The researchers felt that the diagnoses of the two boys were misleading. We find that different diagnoses should imply different characteristics of language difficulty, possibly implying different therapeutic needs. This case study highlights the possible lack of precision when labelling children with diagnostic categories such as SLI. Guendouzi (2003, p. 149) warns that "homogenizing groups of language impaired children in research studies may also lead to homogenizing their therapy". Cognitive referencing may be contributing towards "heterogenizing" LI children into groups based upon criteria which may or may not be meaningful.

To conclude, we found the linguistic profile to be very informative regarding details of the boys' language structure. The boys' strong pragmatic skills allowed their language to present as relatively sound, with attention being drawn towards a weakness of vocabulary. While standardized assessments revealed grammatical difficulties, LARSP displayed precisely where their strengths and weaknesses lay, allowing the SLT to make specific therapy plans, based upon specific needs. Leonard (1998, p. 11) asserts “...standardized test scores serve only as the starting point. The work of actually describing and explaining these children's language functioning must then begin". Linguistic analyses certainly have an important role to play in this work.

\section{References}

Aram, D., Morris, R., \& Hall, N. (1993). Clinical and research congruence in identifying children with specific language impairment. Fournal of Speech and Hearing Research, 36, 580-591.

Ball, M. (1999). Reynell Developmental Language Scales III: a quick and easy LARSP? International fournal of Language and Communication Disorders, 34, 171-174.

Bishop, D. (2004). Specific language impairment: diagnostic dilemmas. In L. Verhoeven, \& H. van Baldom (Eds.), Classification of developmental language disorders: theoretical issues and clinical implications (pp. 309-326). Mahwah, NJ: Erlbaum.

Bishop, D., \& Adams, C. (1990). A prospective study of the relationship between specific language impairment phonological disorders, and reading retardation. Fournal of Child Psychology and Psychiatry, 31, 1027-1050.

Botting, N. (2005). Non-verbal development and language impairment. Fournal of Child Psychology and Psychiatry, 46, 317-326.

Chomsky, N. (1975). Reflections on language. New York: Pantheon/Random House.

Cole, K., Dale, P., \& Mills, P. (1992). Stability of the intelligence quotient-language quotient relation: is discrepancy modeling based on a myth? American fournal on Mental Retardation, 97, 131-143.

Crystal, D., Fletcher, P., \& Garman, M. (1976). The grammatical analysis of language disability. London: Edward Arnold.

Crystal, D. (1982). Profiling linguistic disability. London: Edward Arnold.

De Villiers, J. (2002). Defining SLI: a linguistic perspective. In J. Schaeffer, \& Y. Levy (Eds.), Towards a theory of SLI (pp. 425-447). Hillsdale, NJ: Erlbaum.

Dunn, L., Dunn, L., Whetton, C., \& Pintillie, D. (1982). The British Picture Vocabulary Scale. Windsor: NFER Nelson. 
Eadie, P. (2004). The evidence base for the diagnosis of developmental language disorders; research to clinical practice. In S. Reilly, J. Oates, \& J. Douglas (Eds.), Evidence-based practice in speech pathology (pp. 185-205). London: Whurr.

Guendouzi, G. (2003). "SLI”, a generic category of language impairment that emerges from specific differences: a case study of two individual linguistic profiles. Clinical Linguistics and Phonetics, 17, 135-152.

Krassowski, E., \& Plante, E. (1997). IQ variability in children with SLI: implications for use of cognitive referencing in determining SLI. Fournal of Communication Disorders, 30, 1-9.

Leonard, L. (1998). Children with specific language impairment. Cambridge, MA: MIT Press.

Mawhood, L., Howlin, P., \& Rutter, M. (2000). Autism and developmental receptive language disorder: a comparative follow-up in early adult life. I: cognitive and language outcomes. Fournal of Child Psychology and Psychiatry, 41, 547-559.

Ors, M. (2002). Time to drop "specific" in "specific language impairment". Acta Paediatrica, 91, $1025-1030$.

Raven, J. C. (1998). Raven's Progressive Matrices. San Antonio, TX: Psychological Corporation.

Records, N., \& Tomblin, B. (1994). Clinical decision making: describing the decision rules of practicing speechlanguage pathologists. Fournal of Speech and Hearing Research, 37, 144-156.

Rice, M., Tomblin, J., Hoffman, L., Richman, W., \& Marquis, J. (2004). Grammatical tense deficits in children with SLI and nonspecific language impairment: relationships with nonverbal IQ over time. Fournal of Speech, Language and Hearing Research, 47, 816-834.

Schoenbrodt, L., Kumin, L., \& Sloan, J. (1997). Learning disabilities existing concomitantly with communication disorder. Fournal of Learning Disabilities, 30, 264-281.

Semel, E., Wiig, E., Secord, W., \& Sabers, D. (1987). Clinical Evaluation of Language Fundamentals-Revised (technical manual). New York: Psychological Corporation.

Stark, R. E., \& Tallal, P. (1981). Selection of children with specific language deficits. fournal of Speech and Hearing Disorders, 46, 114-122.

Tomblin, J., Records, N., Buckwalter, P., Zhang, X., Smith, E., \& O’Brien, M., Prevalence of specific language impairment in kindergarten children. Fournal of Speech, Language and Hearing Research, 40, 1245-1260.

Tomblin, J., Freese, P., \& Records, N. (1992). Diagnosing specific language impairment in adults for the purpose of pedigree analysis. Fournal of Speech and Hearing Research, 35, 832-843.

Wechsler, D. (1974). Wechsler Intelligence Scale for Children-Revised. New York: Psychological Corporation.

Whorf, B. (1956) Language, thought and reality (Ed., J. Carroll). Cambridge, MA: MIT Press. 